\author{
MILITARY TECHNICAL COLLEGE \\ CAIRO-EGYPT
}

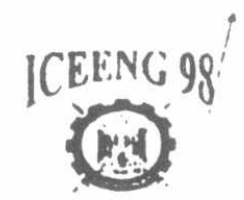

FIRST INTERNATIONAL CONF. ON

ELECTRICAL ENGINEERING

\title{
Automation Support for Concurrent Software Engineering
}

\begin{abstract}
Salah Badr*
A BSTRACT

This paper presents an evolution eontrol system that provides automated assistance for the software evolution process in an uncertain environment where designer tasks and their properties are always changmg

We view an Evolution Control System (ECS) as the ogent that keeps track of proposed, ongoing. and completed changes to a software system. It provides auto mated assistance to the software evolution manager to help him/her make the right decisions. It automatically propagates change consequences by constructung the set of possibly affected modules It also coordinate's change implementation activities within the design team in a way that supports team work and maintains system integrity, as well as adaptung itself to the dynamic nature of the evolution process where new changes arrive randomly and ongoung moditications arc themselves subject to change as more intormation becomes available
\end{abstract}

\section{A. INTRODUCTION}

An ECS has two main functions The first is to control and manage evolving software system components (version control and configuration management. VCCM) and the second is $t o$ control and coordinati evolution team interactions in a way that maximizes the concurrent assignment and meets management constraints such as deadlines and precedences (planning and scheduling software evolution tasks which we refer to as evolution steps)

This system provides the required algorithms for coordinating and executing the activities mentioned above as well as the algorithms for reaching and maintaining a feasible schedule, if one exists, that meets the deadline requirements, reduces/avoids rollbacks, and insures system integrity in an uncertain environment where the set of evolution steps and their properties are always changing

\section{B. PREVIOUS WORK}

The main areas in software engineering relevant to ECS are software developmentevolution, version control and configuration management, task planning and scheduling, and concurrency control

\section{FORMAL EVOLUTION MODELS}

in [9], Luqi presents a graph model for software evolution that introduced the notion of evolution step as the activities of initiation analysis and implementation of one request for change in the system under evolution. The graph model represents the software system evolution history as an acyclic bipartite graph $G=\{C, S, 1$. O) C nodes represent system components and S nodes represent evolution steps. The input edges I represent the relation between a step and the set of system components that have to be examined to produce output components that are consistent with the rest of the system. The output edges $O$ represent the relation between an evolution step and the components it produces. The states of an evolution steps as well as the generation of substeps to propagate the change consequences are also defined. In this paper we extend this graph mode! to include other relations among system components ("part_of" and "used_by") and the "partof" relationship between composite step and its substeps

Unlike the original development cvele. the evolution activities (adaptive, corrective, and pertective maintenance) must take into consideration the existing system s requirements, decomposition. constraints. capabilities and performance. The effect of the changes must be propagated to preserve svstem consistency In the mean time, concurrent changes must be coordinated to avoid rollbacks and wasting engineenng effort Evolution changes must be planned so that ther meet the management constraints such as deadlines.

* 1. Ir Saliah Badr is the chict of intornatuon svstems hranch. Armament Authorits of the Egyptian Armed forces 
Proceeding of the $1^{\text {st }}$ ICEENG conference, 24-26 March. 1998.

each path that has only I and ( ) edges Thes represents the evoluton history vew of the graph the edges represent the "part_of" (heteven a sub-component of a composite component and the compesite component) and "usid_by" relations (delined between components to represent the sttuation where the semantics of implementation of one component $A$ depends on another component 13:13 used by A) between the settivare

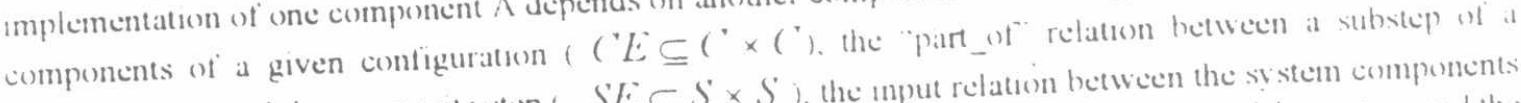
composite step and the composile step $S E \subseteq S \times S$ i. the mput retatem between the sytem components which must be examined to produce output eomponents that are consistent with the rest of the sitstem and the corresponding evolution steps $I \subseteq\left({ }^{*} \times S\right)$, and output relation between evoluten steps and the components they produce $\left(C \subseteq S \times\left({ }^{\prime}\right)\right.$. System eomponents are immutable versions of software source objects that ciannot be reconstructed automatically

An "edge_type" attribute is used to distmgunsh hetween the (wo) kinds of edges represienting the relations used by" and "part_of" detined on the set of edges ( $E \subseteq C \times\left({ }^{\prime}\right.$. The "used_by relation cian be used fior automatic identification of inputs of proposed evolution steps and identification of the induced steps triggered by a proposed step.

The model distunguishes between the primary and secondary mputs of a step. The primany input concept cin be formalized hy introducing the attributes object_id. version_ld and vanation_id of each version. Vanations represent diternative choices. which may correspond to different fonmulations of the requirements in the contest of prototyping, or different kinds of system software (operating system, window manager. etc. ) m the context of product releases. Fach vanation is a linearly ordered secpuence of versions. An unput to a step is promary if and only if it 1 the prevous version of the same object and helongs to the same varnation als the rutput of the step

\section{Version and Variation Numbering}

As seon as the input base version of a step is hound. the syitem assigns the version and variation number of the output object for the step. The varnations are assigned successive numbers beginning with I for the initlal Caration. Versions along each vartation are assigned successive numbers starting with 1 at the root version

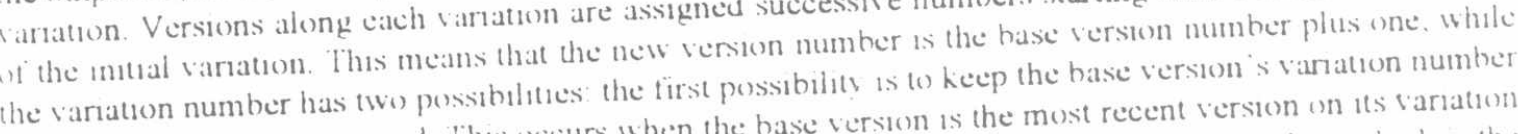
the tume the step is assigned this aceurs when the base version is the most recent version on its variation me at the ume the sten is assigned. The other posisbility is to use the "next" variatum number. which is the

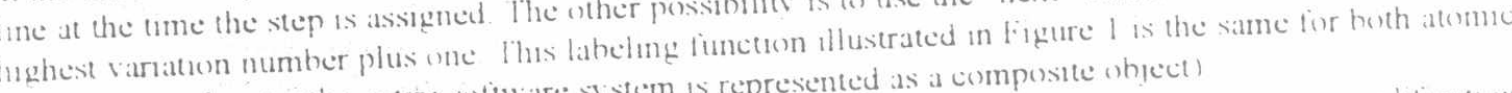
ir composite objects (the entre software si stem is represented as a composite ohject)

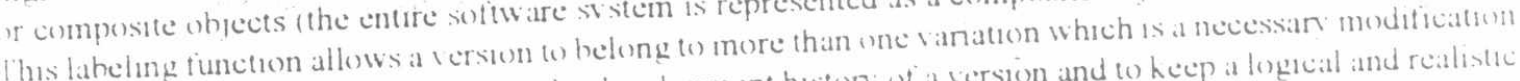
11) (9) to sumplify the process of tracing the development history at a version and to heep a logicial and realistec development histor:

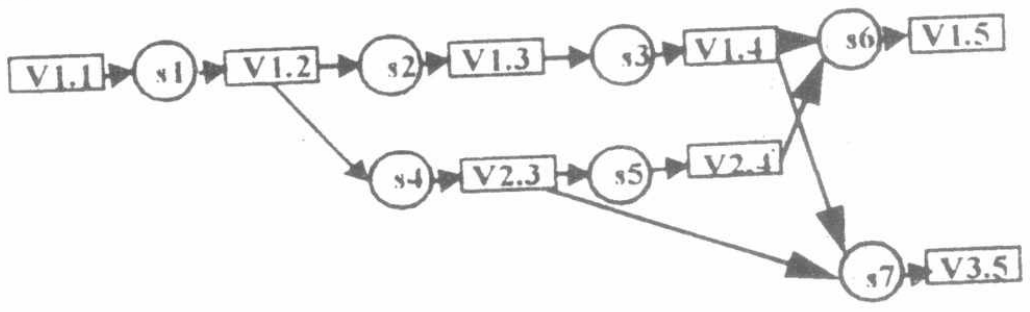

FIGURE 1. Variation and version numbering

\section{States of Evolution Steps}

ics of the evolution steps are modeled by associating six different states with each step to express itep has to undergo dunng its lifetime. The state transition diagram in Figure 2 the different actuvities eas se made by the magement to cause the transition from shows the different explicit deersons that hase atomated transitions from the scheduled state to the assigned state wne state to the other. It also show. and vice versa (explained in detanl in subsections $c$. and d belowi By controlling the states ol the evolutong 


\section{a. Scheduling Tasks with Precedence Constraints}

Sicheduling tasks with arbitrary precedence constramts and und computation tune in multuprecessor sy stems

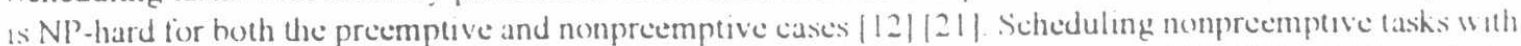
arbitrary ready times is $\mathrm{Nl}$-hard in both multiprocessor and umprocessor systems $|12| \mid 2(0)$ which excludes the possibility of the existence of a polynomial tume algorithm for solving the problem. Ifong and l. eump $|+|$ proved that there is no optimal on-line scheduler can exist for task systems that have two or more distunct deadlines when scheduled on m identical processors where $m>1$

sicheduling evolution steps to more than one designer with arbitrary precedence constrants and arbitrary deadlines is the same problem as that of multiprocessor scheduling mentioned above which is shown by many researchers to be NP-hard. These negative results dictate the need for heuristic approaches to solve seheduling problems in such svitems

In [ $[6]$ Stankovic et al present an ()$\left(\mathrm{n}^{2}\right)$ heuristic scheduling algorithm for scheduling a set of independent processes on a set of identical processors. A task (process) in this model is characterized by an amrival tume $T_{1}$, a deadline $T_{D}$, a worst case computation tume $T_{C}$, and a set of resource requirements $T_{R} ;$. Tashs are independent, non periodic and non-premptace In | 12|. Ramamritham et al. introduce an ()(nk) lersion al the algorithm introduced in |l6| hy considering only $h$ tasks of the remaining tasks to be scheduled at each step. We have extended this algorithm to deal with precedence constraints and expertise levels of designers |1]

\section{CONCEPTUAL MODEL}

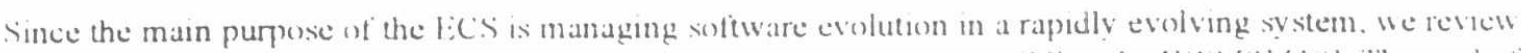

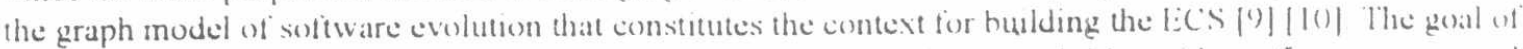
this model is to provide a framework fior megratung software evolution activities with contiguratuon control [9]. The model of software evolution has two man elements sy stem eomponents and evolution steps. Syystem components are immutable versions of software source objects that cannot be reconstructed automatically livolution steps are changes to ststem complonents that have the following properties in the originat version "f the graph model |')

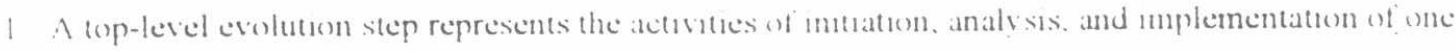
change request

2 In evoluton step mav he esther atomic or composite

; An atomic step produces at most one new version of a st stem component. Thes property as mo longer the In our model on order to include the cases in whoth an atome step is applied to an ongmally atome component that needs to be decomposed aceording to some destgn consideratons. Thes decompositum mats

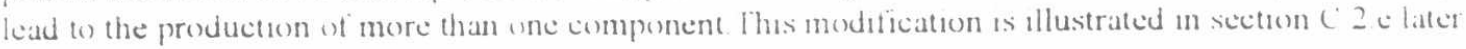
in this chapter.

I The inputs and outputs of a composite step correspond to the inputs and outputs of its substeps

5 The model allows steps that do not lead to the productuon of new eontigurations. e g. design alternatues that were explored but not included in the configuration repository.

1. Completely automate transtormations are not considered to be steps and are not considered in this mudel.

7 The graph model can cover multuple sy stems which share components, altemative variatuons of a single svstem. and a series of configurations representing the evolution history of each altemative vanation of a siv stem

$x$ A seope is associated with each evolutuon step which identifies the set of systems and variations to be affected by the step. The scope is used to determine wheh induced evolution steps are implied by a change request.

The evolution history is modeled as a graph ( $;=\mid C$. S. LE. SF. I. () ). This graph is a directed acyelic graph (bipartite with respect to the edges $I$ and ()$)$. C' and $S$ are the two kinds of nodes ( $C^{\prime}$ software component nodes, and s: evolution step nodes respectively). Each node has a unique identifier. $C$ and ${ }^{\prime}$ nodes aiternate 
Including the evolution steps, wh all the data dhey have about the change thev implement, as nodes in the hipartite evolution history graph facilitates evolution hustory tracing. ( ) ur concept of composite entutes and its generalization to fit sy stem configurations is also simiar to that used in PACT 1131. ()ur system uses a computed labeling function and a single versionme mechamsm fir automatically versioning individual objects as well as configunng a system (as a composite object) simplifying version control and contiguration management and making it transparent to the user without requiring his/her intervention, as it is the ease in our system, are two of the main goals of a geod sersion control and contiguration management system as set forth by feldman in $[4]$

According to Kaiser and Perry |f| the man tools that propagate changes among modules are listed befow However. none of these support the enforeed model of eooperation among programmers necessary for lade maintenance/evolution projects or automatically assign tasks to programmers

Make: a IJNIX tool that is used for regenerating up-(o-date executables after source objects have heen changed

Buld: is an extension (o) make that pernat vartous users to have different views of target software sy stem. (iedar: the Cedar Sivitem Modeler uses an advanced version of the Make tool with version control to invoke the tools on a spectic versions of tiles. This Sistem informs the "Release Master", a programmer, about ans syntactic interface errors. The Release Master is responsible for making work arrangements with responsible programmers

DSEE the Apollo Doman Software Engunerang Environment also uses a Mahe-like tool with version control. DSEE also has a montorng facility that permits programmers and/or managers to request $(1)$ he notulied when eertain inodules are changed.

Masterscope: Interlisp is Masterseope (o)d mantams cross-refierence infonnation betoveen program unuts automatically. It also approximates change analysis of potental interterence between changes by answerng yuenes about syntactic dependencies among program unts.

SVCE: the (iandalf System Version Control finvironment performs incremental consistency checking across the modules in its database and notifies the programmer of errors as soon as they oceur. The consistency checking is limited to sintactic mterface ertors. It supports multuple programmers working in sequence but does not handle smultancous changes.

Katser and Perry $|+||7||11|$ also describe Infusce a system that atutomates change management hy entoremg programmer cooperation to mantian consistency among a secpuence of scheduled source code changes. Infuse automatically partitons these modules into a herarchy of expermental databases but programmers are

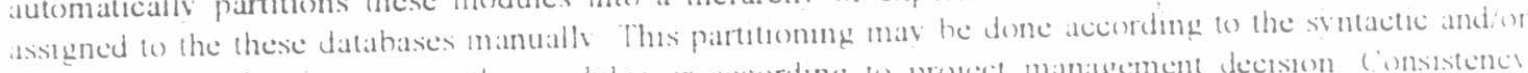
semantic dependencies among the modules of according to propect management deciston (ionsistence checking among the experimental database modules is a pre-conditon tor mergmg a databise back to lls parent expenmental database a meanng that the mortace between the modules must he correct and that the modules can compile and link successtully).

In our system tasks and copies of the associated versions of software components are assigned automaticalls (1) designers (programmers) according to ther dependencies. Versions are generated automatically as soon as the work is done Syntactic and semantic consistency checking for source code can be implemented by associating declarations of consistency constrants with steps. and triggerng the requred checking actions as part of the commit protocol.

\section{APPROACHES TO SCHEDULING EVOLUTION STEPS}

A scheduling problem in a real-tume system is described by three hasic enncepts: the model of the system. the characteristics of the tasks to be scheduled. and the objective of the scheduling algorthm |12|

Task scheduling in real-tıme systems can he static or dynamic. A static approach pertiorms the calculation of the schedules tor tasks off-line. It requires pror knowledge of the charactenstics of the tasks. (On the other hand. a dvnamic approach calculates schedules for tasks "on the tly" Static approaches have low run-time cost, but they are inflexible and cannot respond to a chianging environment with unpredictable behavior Dvnamie approaches involve higher run-tume costs, but thev are thexible to adapt to environment changes. A survey of static and dy namic scheduling approaches can be found in $|12|$

Task scheduling can also he characterized as preemptive and nonpreemptive A task is preemptace if us execution can be interrupted by other tasks and resumed afterwards. A task is nonpremptive if it must run to completion once it starts. 


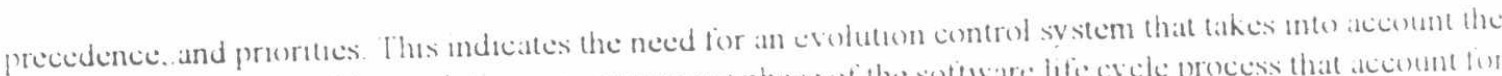

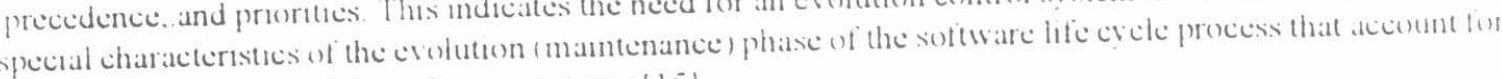
up to $75 \%$ of the cost of the sortware systems $|15|$

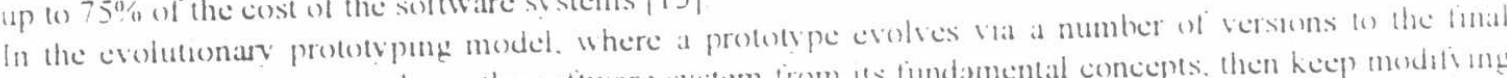

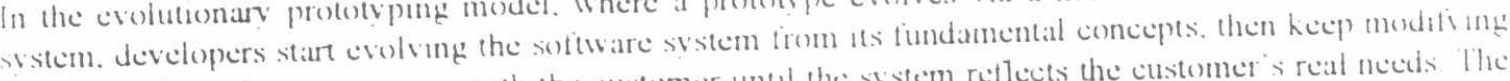

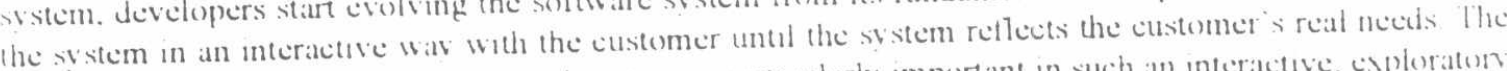

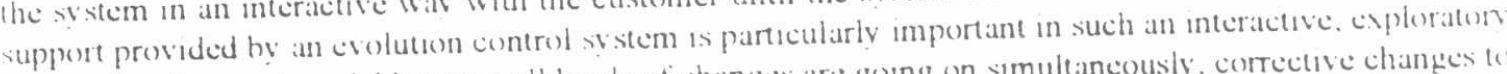
sistem development model hecause all kinds of changes are gong on simultancously. corrective changes to retlee the real customer repurements after reviewng the designer s interpretation of portions of the developed requirements, adaptere changes to the rest of the customer s real needs. and pertectave changes to the fundaunental concepts adready acepted by the custemers. The interactions between these different activities, the coordination anong related ones, propagateng the effects of each of these changes to the rest of the developed modules, and keepung track of which component belongs to which system version are the man Hoals of our evolutun control sistem

\section{VERSION CONTROL AND CONFIGURATION MANAGEMENT}

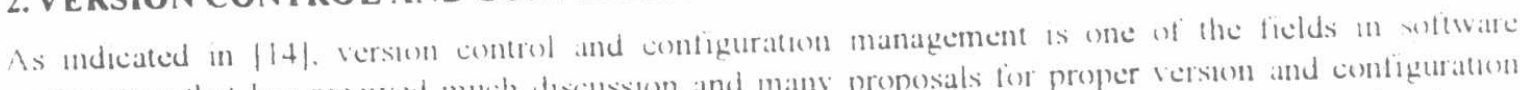
enguncerng that has recelved much discussion and many proposals for proper verson and contiguraton models in ditierent domans. hut hate has been implemented, and much remans to be done in detelepmp

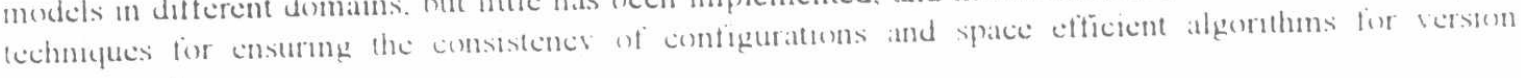
management.

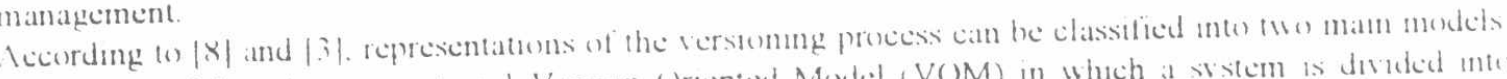

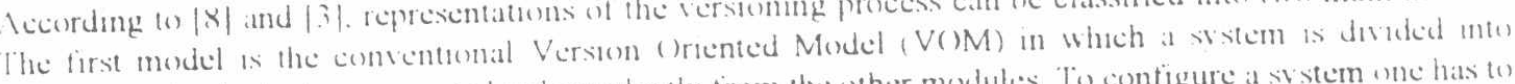
modules each of wheh is versioned undependently from the other modules. To contigure a st stem anc has to select a version of each module of the ststem. This makes version a promary concept while change 15 a

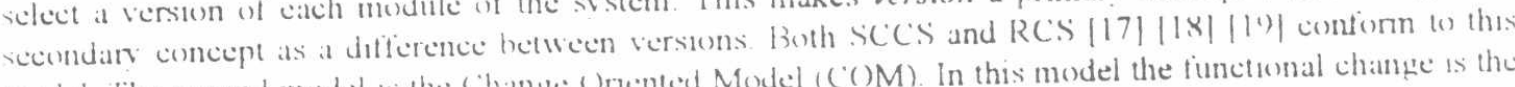
model. The sceond model is the ( hampe ()nented Model ( ( ()M). In this model the functunal change is the

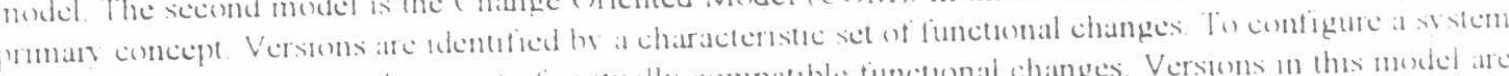

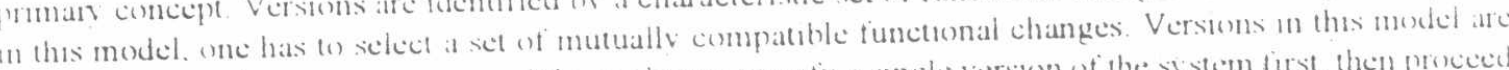

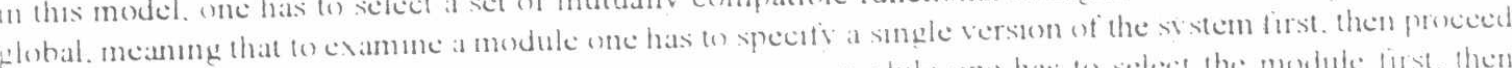

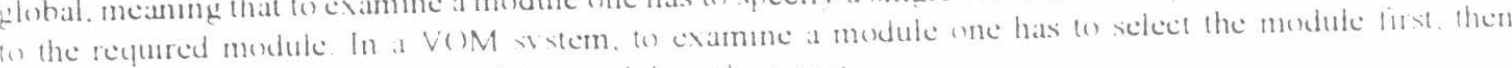

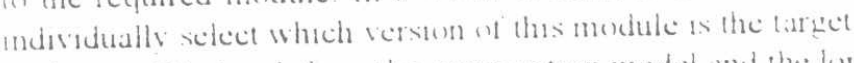

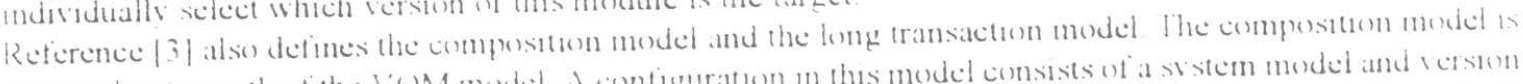

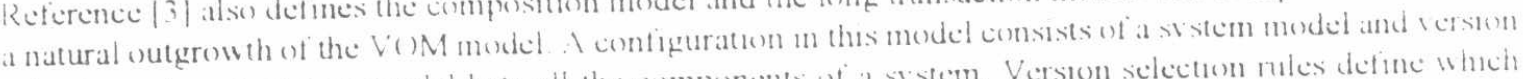
selecton rules A ststem moded lists all the components at a ststem. Verston selectun miles defme wheh

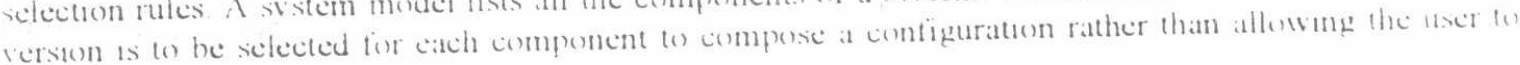
manually peck component versioms

The long transatoon model supponts the evoluton of whole ststems as a sequence of apparents atomic changes, and coordinates the change of sottware systems be teans of devetopers. Detelepers woth promaris

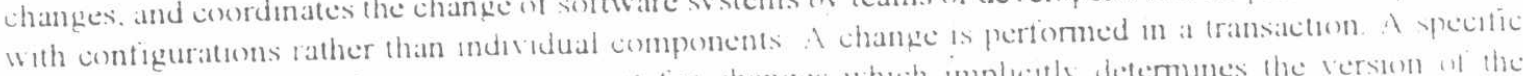

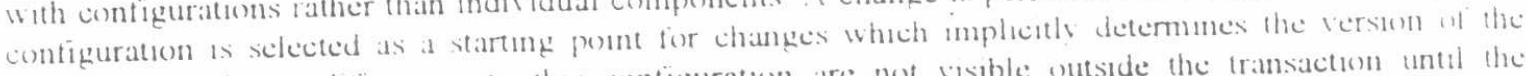
components. The moditications to this configuration are not visible outside the transacton until the transaction is committed. Multiple transactions are coordinated via concurrency control schemes to guarantes 11) loss of changes. The result of the committing of a transaction is a new svstem contiguratuon versten cuthes on the same development path or branch from an exsstung development path resultung un a ncw altematte (vartation) development path

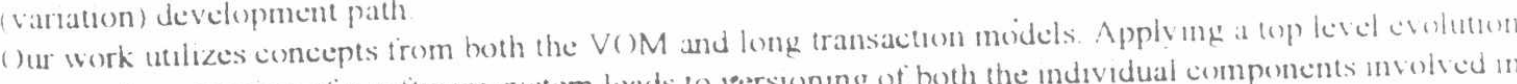
step to a base version of a software sy stem leads to versioning of hoth the individual components involiced in the change and the enure software sv stem producing a newe eonfiguratun version (version of a whole st stem) In addition our svitem automatically coordinates teamwork in such a wav that concurrency control is done at a hagher level of abstracton. I e the serialization of dependent evolution steps is done by serializing then assignment to developers in the sance order and excluding the need for the tradiunal locking ichemes 
then the step status is automatically advanced to "assigned" and the designer is informed of the new assignment. When a step is assigned, the version hendings of its inputs are automatically ehanged trom generic to specitic. An edge is added as an input edge between the primany input ecomponeme of the step and the step itself in the contiguration graph

\section{e. Completed State}

In this state the outputs of the step have been verified. integrated. and approved lor release. This is the fint state for each successtully completed step. This state ean only be reached from the assigned state using the commit_step" command. In this state the output components of the step have been added to the eontigeturation graph. An output edge has also been added to the contiguration graph between the step and its output component(s). A composite step enters the eompleted state when all of its substeps are completed

\section{f. Abandoned State}

In this state the step has been cancelled before it has been completed. The outputs of the step do not appear as components in the evolution history graph. All partial results of the step and the reasons why the step is abandoned are stored as attributes of the step for future reterence. This is the tinal state for all steps that were not approved by the management or cancelled in the "approved". "scheduled" or "assigned" states.

\section{SCHEDULING MODEL}

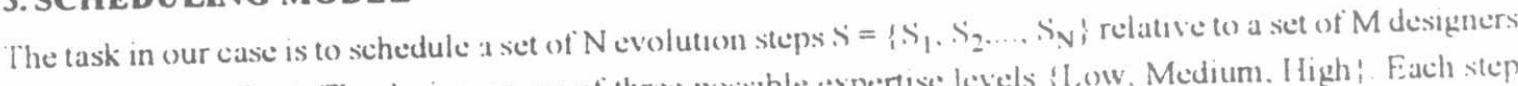
$1)=\left\{D_{1}, D_{2}, \ldots . D_{M}\right\}$. The designers are of three possible expertise levels \{low. Medium. High $\}$. Each step has associated with it a processing time tp $\left(S_{i}\right)$, a deadline d $\left(S_{i}\right)$, a priority $p\left(S_{i}\right)$, and required expertise lesel e $\left(S_{i}\right)$. Steps have precedence constraints given in the form of a directed acyclic graph $(j=(S)$. E) such that $\left(S_{i}, S_{j}\right) \in E$ implies that $S_{j}$ cannot start until $S_{i}$ has completed.

Because of the dynamics of the prototvping/evolution process, the steps to be scheduled are only partiaily known. Time required. the set of sub-tasks for each step. and the input/output constraints hetween steps are all uncertain, and are all subject to change as evolution steps are carred out

() ur goal is to dynamically determine whether a sehedule the tume periods) for executing a set of evolution h that the timuse precedence, and resource constrants are satistied. and (1) calculate this schedule if it exists

\section{DESIGN}

The purpose of the Evolution Control tivstem. LCS. Is to provide automated suppon for changes in plan luring the execution of the plan. and provide automatic decision support for plannmg and team coordination hased on design dependencies eaptured in the configuration model. The ECS also manages the sottwite evolution steps trom its creation to completion and provides automatic version control and configuration management for the products of these steps.

\section{a. Context Model}

The Evolution Ciontrol Svstem (EC'S) interacts ivith (Ivo) external entities: the sot tware evolution manager and the software designer These represent classes of human users rather than external software or hardware sistems. There is one external intertace for each class of user the manager intertace and the designer intertace. Both of these intertaces are views of the proposed ECS. The message tlow diagram in Figure 3 and the stimulus-response diagrams in Figures $7,8.9$ and 10 show the context of the system and the available commands, their effects and the possible error conditions

\section{State Model And Related Concepts}

The state of the EC'S consists of a configuration graph, a schedule, a set of designers, and mappings giving the following attributes for each evolution step: deadline. estimated duration. precedence, priority, status and required expertise level. The formal detinitions of the state model and the constraints on a feasible schedule are defined in [1] 
Proceeding of the $1^{\text {st }}$ ICEENG conference, 24-26 March, 1998.

steps, the evolution manager exercises direct control over both software evolution/development and the resulting software configurations. The following are the detinitions of those states and the corresponding actons that cause the transition from one state to the other. These states are similar fo those presented in $|9|$ except that a new state called "assigned" has been added for the reasons explained below

\section{a. Proposed State}

In this state a proposed evolution step is subjected to hoth cost and benctit analysis. This analysis also includes identifying the sottware objects comprising the input set of the step. A "propesed" step is generally added to the contiguration graph as an isolated step node that does not have any input, output or part_of edges (except when an old version is used that has existing specific reference). This is because the primary and secondary input attributes are mostly generic inputs (object_id and variation_id only)

\section{b. Approved State}

In this state the implementation of the step has been approved but not scheduled yet and the input set of the step is not bound to particular versions. Approval of a proposed step by the management triggers the decomposition process to create an atomic sub-step for each primary or affected component of the step. These sub-steps inherit the status of their super-step which is "approved" in this case. and are added to the contiguration graph with a part_of edge between each sub-step and its super-step. It is also in this state that the substeps are augmented with attributes that include the estimated duration of each sub-step and management scheduling constraints such as precedence, deadline, and priority.

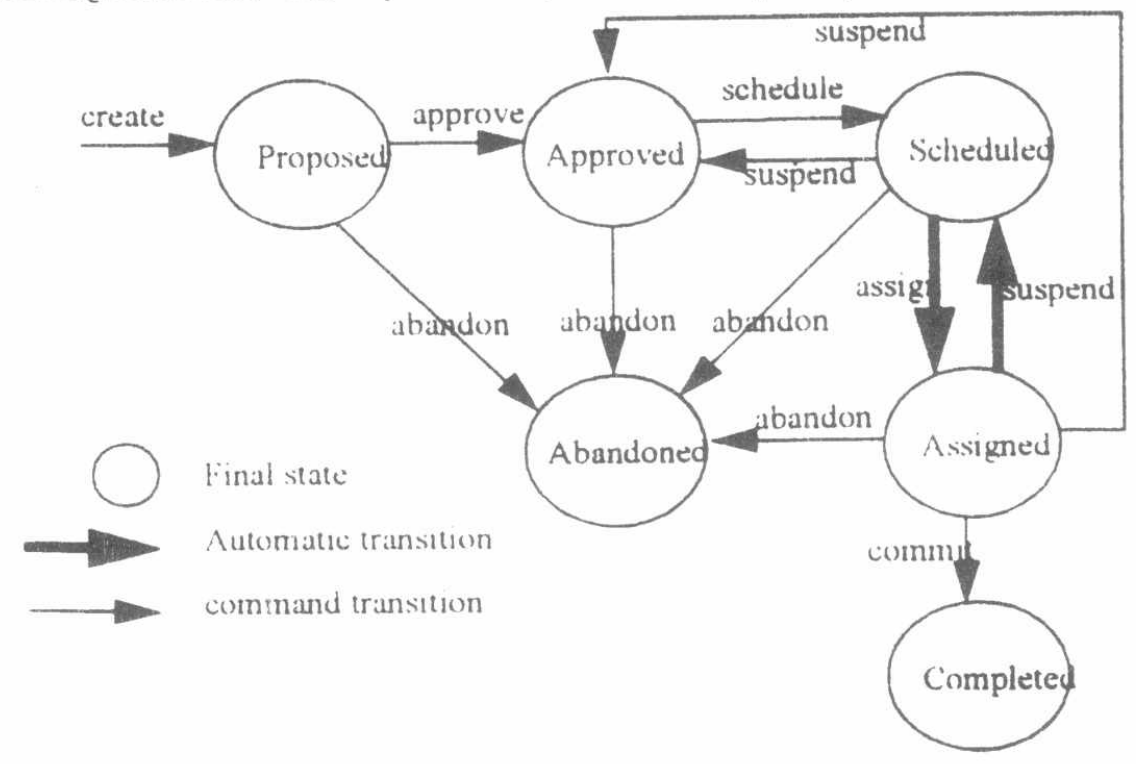

FIGURE 2. Evolution step's state transition diagram

\section{c. Scheduled State}

In this state the implementation has been scheduled and the step is not yet assigned to a designer. The "scheduled" state is reached from the "approved" state via the command "schedule_step" that indicates that the management constraints are complete and enables the scheduling and job assignment mechanisms. The scheduling mechanism produces an updated schedule containing the newly scheduled step. A schedule specifies the expected starting and completion times for the step.

\section{d. Assigned State}

In this state the step is assigned to the scheduled designer, all inputs are bound to particular versions, and unique identifiers have been assigned to its output components, but these components are not vet part of the evolution history graph. A composite step enters the assigned state whenever any of its substeps is assigned. The assigned state is reached automatically from the scheduled state. When a designer is available, the schedule is used to determine his/her next assignment. If his/her next assignment is ready to be carried out 


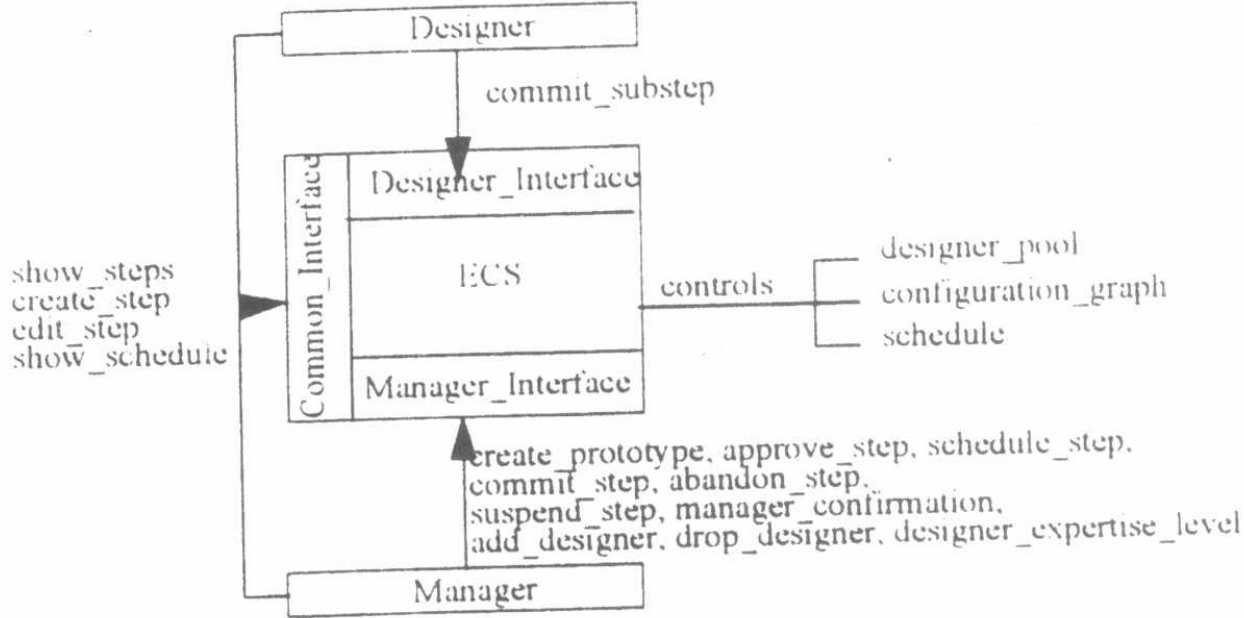

FIGURE 3. ECS message flow diagram

\section{Interfaces}

The manager intertace $(1)$ the ECS enables the manager to create new prototypes, provide for the evolution of the existing protolypes via a complete set of esmmands for creating, editing. scheduling, suspending/ abandoning and/or cormmitting evolution steps. and manage the designer_pool data via add_designer. drop_designer, and designer_expertise_level commands. The designer intertace to the EC'S enables the desigrer to view the stess in a given prototype with a given status and get the sub-steps assigned to hin. This

interface also enables the designer to create a sub-step of an assigned step as well as committing the assigmed ub-ite The formal specifications of the vanous commands with the different responses for each command are defined in $|1|$

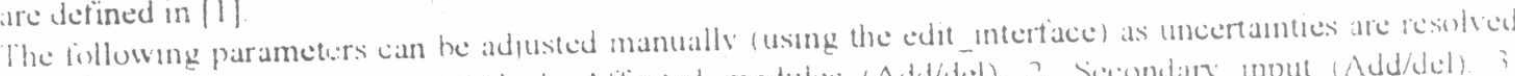

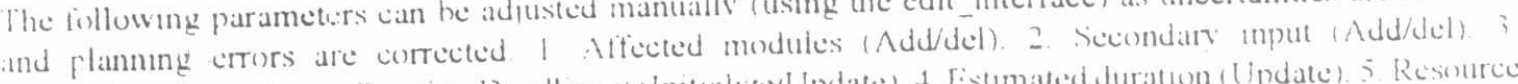

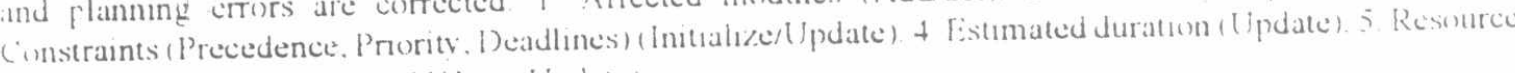
(1)estpner P(w)l Changes) (Add/drop. I ipdate)

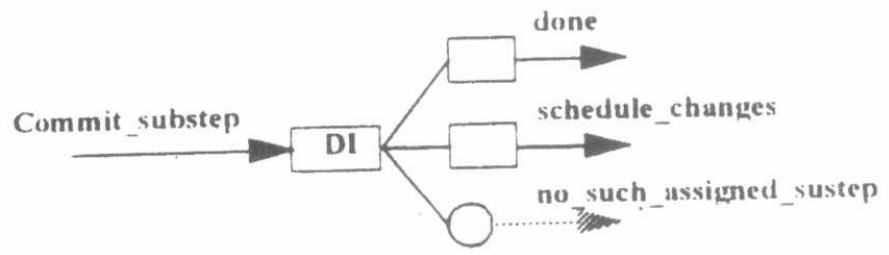

\section{FIGURE 4. Stimulus-Response diagram for the designer interface}

The sichedule_step command tnggers the scheduling mechanism that finds a feasible schedule if one exist of suggest changes to the deadlines of the lower priority steps until a feasible schedule is reached. When a designer is available for his assignment the ECS automatically checks out the required components from the design database to the designer's workspace and sends an e_mail message to the designer intorming him about his new assignment. When a designer tinishes his assignment, he simply issues the commit step command. The system then automatically checks in the modified components to the design database giving them the right version and variation numbers and binding them to the approprate configuration. The EC'S automatically monitors changes in plan and takes the appropnate action to maintain the required constraints 

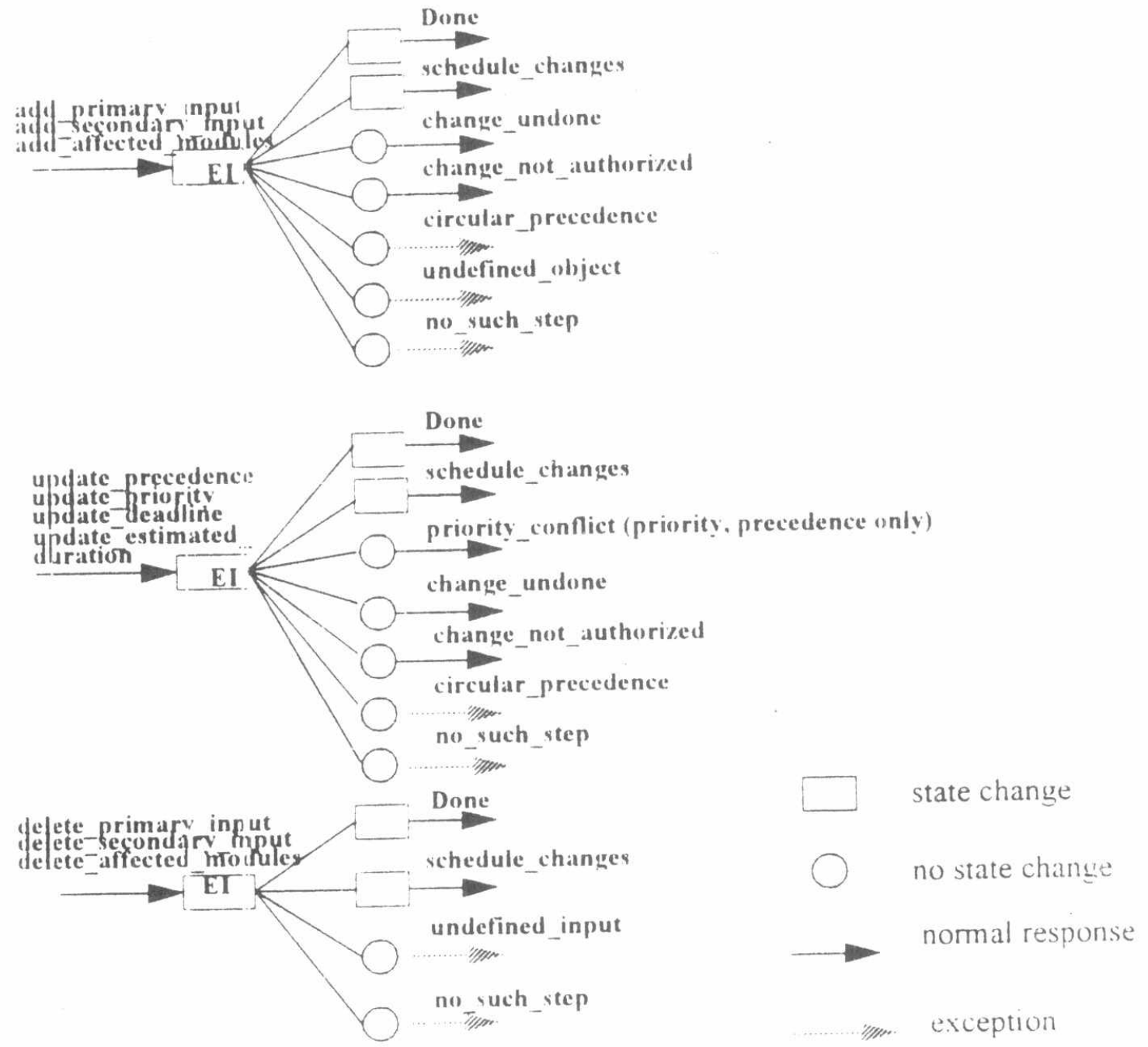

FIGURE 5. Stimulus Response diagram for the edit interface

\section{E. CONCLUSION}

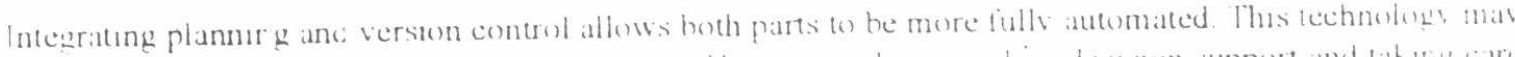

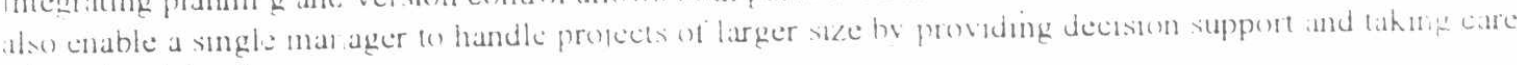
uf low level detail: 

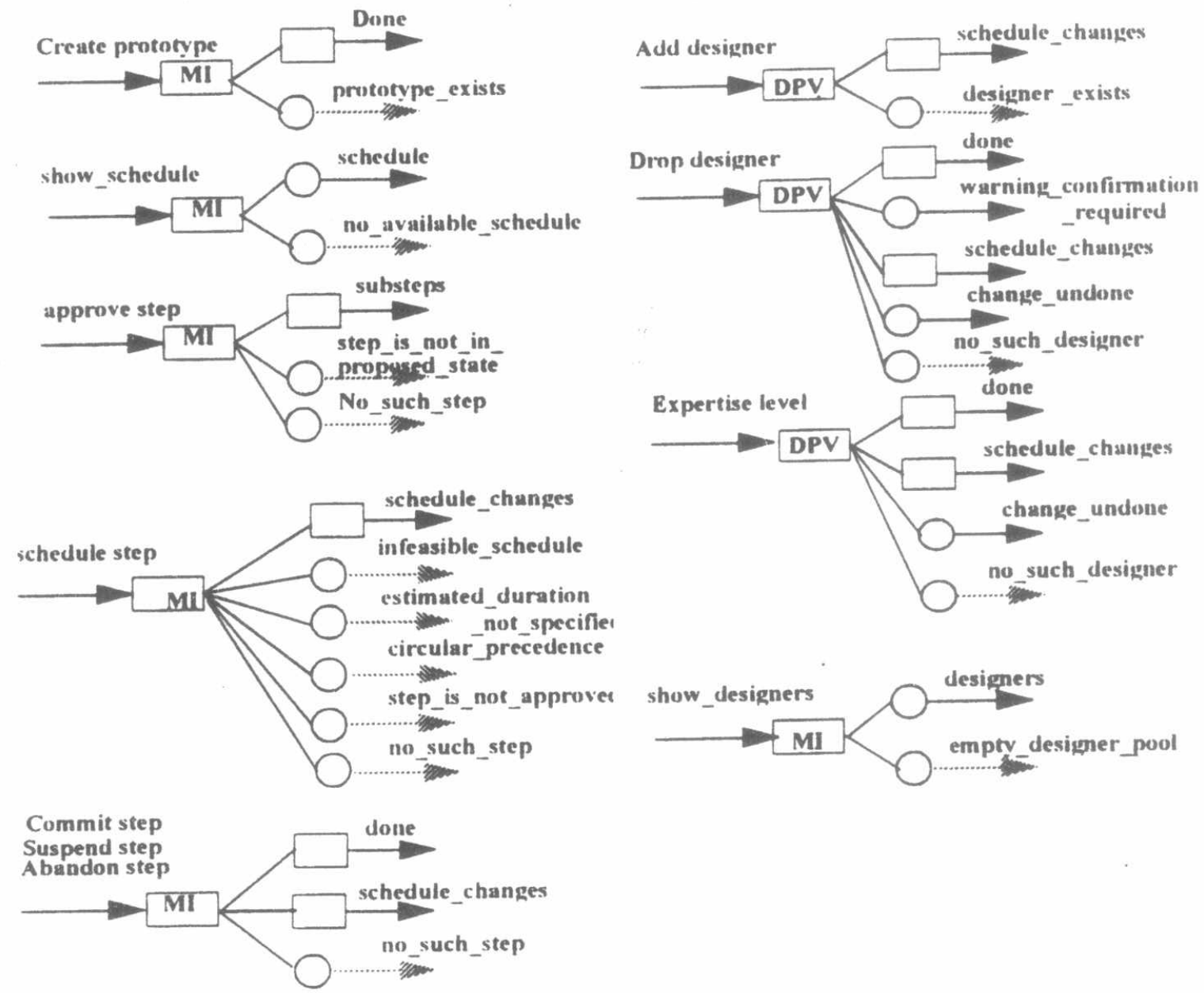

FIGURE 6. Stimulus Response diagram for the manager interface

\section{REFERENCES}

(1) Badr Salah. "A Model and Algorithms for a Software Evolution Ciontrol System". Ph. D Dissertation. Computer Sicience Department. Naval Postgraduate ichool. December 1993.

(2) Dampier D. Luqi, “A Model for Merging Software Prototypes”. Technical Report. NPS CS-92-014.

(3) Feiler P. H., "Configuration Management Models in Commercial Environments". Technical Report CMU-91-TR-7, ESD-91-TR-7. 1991.

$1+1$ Feldman S. I., "Software Configuration Management: Past Uses and Future Challenges" Proceedings of 3rd European Sottware Engineering Conference, ESEC '91. Milan. Italy, ()ctober 1991

(5) Hong K. and Leung J., "On-Line Scheduling of Real-Time Tasks" Real-Time Systems Workshop. May 1988.

[6] Kaiser G. E., and Perry D. E., "Workspaces and Experimental Databases: Automated Support tor Soltware Maintenance and Evolution". Proceedings of IEEE Cionference on Sottware Maintenance 1987. pp. 108-114. 
Proceeding of the $1^{\text {st }}$ ICEENG conference, 24-26 March, 1998.

(7) Kaiser (4. E., and Perry D. E., and Sichell W. M. "Intuse: Fusing Integration Test Management with Change Management". Proceedings of the Thiteenth Annual International Computer Software \& Applications Confierence, (Orlando, FL, September 2()-22, 1989)

$|8|$ Lie $A$ et al, "Change ()riented Versioning in a Situvare Engincering Database", Proceedings of 2 nd Intemational Workshop on Software Configuration Management, Princeton. New Jersey. ()et 24.1989. pp. 56-65.

(9) Luci, "A (iraph Model for Software Evolution". IIEE: Transaction on Soltware Enginecring. Vol. I0 N(). 8. Aug. 1990. pp. 917-927.

(10) | Mostov I., Luqi, and Hetner K., "A (iraph Model for sottware Maintenance". Tech. Rep. NPS52-4)()014. Computer Science Deparment, Naval Posigraduate School. Aug. 1989)

1 11 | Perry D. L., and Kaiser G. E., "Infuse: A Tool for Autonatically Managing and Coordinating Source Changes in Large Systems", Proceedings of the 1987 ACM Fiftenth Annual Computer Sictence Conterence. St Louis, Missour, February 1987. pp 292-2)9.

| 12 | Ramamntham K. Stankovic J. A. Shiah P. "Ethicient Sicheduling Algorithm for Real-Time Multiprocessor Systems", C(OINS Technical Report 89-7. Dept. of Computer and Intiormation Science, University of Massachusetts, 1989

1 13 | Simmonds Ian. "Configuration Management in the PAC'T Sottware Enginering Environment" Proceedings of 2 nd International Workshop on Software C'onfiguration Management. Princeton. New Jersey, ()ct. 24,1989. pp. 118-121

(14) Silberschatz A.. Stonebraker M.. and IJllman J. "Datanase Svstems: Achievements and ()pportunities". Communication of the ACM, ()ctoher 1991/Vol. 34. No. 10, pp. 110-120.

[15] Sommerville lan "Sottware Engeneering". Fourth edition. Addison-Wesley 1992

| 16 | Stankovic J. A., Ramamntham K. Shiah P. and Zhao W. "Real-Time Scheduling Algorithms tor Multiprocessors". COINS Technical Report 89.47.

$117 \mid$ Tichy W. F. "RCS-A Sivstem for Version Control", Software Practice and Experience. V()L. 15 (7). July 1985 pp $037-054$

$|18|$ Tichy W F. "Tools for Software Configuration Management". Intemational Workshop on Sottware Version and Contiguration Management", (irassau, FR (; 27-29) January 1988

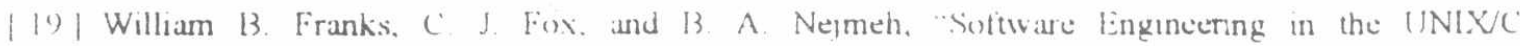
Environment", Prentice Hall 199)

120) Xu Jia.. "()n Satistying Timing Cinstraints in Hard-Real-Time systems". IEEE Transactions on Suttware Engineering. Vol. 19. No. 1. January 1993

| 21 | Xu Jia., "Multiprocessor Scheduling of Processes with Release Fimes, Deadlines. Precedence. and Exclusion Relations“. IEEE Transactions on Software Engincering. Vol. 19. No. 2. February 1993 